\title{
Acoustic Emission Properties of Concrete Slab During Fatigue Testing with a Running-Wheel Load
}

\author{
Mitsuharu Shiwa ${ }^{1}$, Zhengwang $\mathrm{Li}^{2}$, Takuya Maeshima ${ }^{3}$, Yasuhiro Koda ${ }^{3}$ and Yasushi Tanaka ${ }^{4}$ \\ 1. National Institute for Materials Science, Tsukuba, Ibaraki, 305-0047, Japan; \\ 2. Nippon Physical Acoustics, Ltd., Tokyo, 150-0011, Japan; \\ 3. Department of Civil Engineering, College of Engineering, Nihon University, Koriyama, Fukushima, 963-1165, Japan; \\ 4. Institute of Industrial Science, The University of Tokyo, Tokyo, 153-8505, Japan
}

\begin{abstract}
AE (acoustic emission) signals from concrete slab during fatigue testing with a running-wheel load were evaluated. The signals were recorded by remote sensors connected to a computer network. The sensing equipment consisted of $60 \mathrm{kHz}$ resonant-type AE sensors mounted on a reinforcing steel bar as a waveguide, together with a 16-channel sensor highway AE system. Because the detected AE signals included periodic mechanical noise from the motion of the wheel, these noises were eliminated by means of signal processing. The AE waveguide measurement over a length of $3 \mathrm{~m}$ detected fractures as vertical and horizontal cracks in the RC (reinforced concrete) slab. Those cracks were analyzed by correlating AE parameters with macroscopic distortions and the numbers of fatigue cycles. In the $\mathrm{AE}$ events and $\mathrm{AE}$ energy, two types of $\mathrm{AE}$ phenomena, active region and inactive region, were observed during fatigue testing. The vertical cracks were characterized by an AE amplitude of $58 \mathrm{~dB}$, a peak frequency of $30 \mathrm{kHz}$, and a ratio of the rise time to the maximum amplitude value (RA) of 100 . The horizontal cracks were characterized by an $\mathrm{AE}$ amplitude of $85 \mathrm{~dB}$, a peak frequency of $60 \mathrm{kHz}$, and an RA value of 10 .
\end{abstract}

Key words: Acoustic emission, concrete slab, waveguide, fatigue testing, running-wheel load.

\section{Introduction}

Deterioration of RC (reinforced concrete) slabs in highway bridges is a severe problem in bridge engineering. Through fatigue testing with running-wheel machines developed in Japan, failure mechanisms and fatigue strengths of RC slabs have been clarified. For example, Matsui developed a running-wheel load machine to evaluate fatigue damage to an RC slab [1]. Generally, the durability and the performance of an RC slab are estimated from the density of cracks formed on its bottom surface. The degree of damage to a slab can be classified on the basis of the density of cracks on its bottom surface as, for example, in the Standard Specification for Concrete Structures of the Japan Society of Civil

Corresponding author: Mitsuharu Shiwa, Dr., managing researcher/assistant section manager; research field: Non-destructive evaluation for materials. E-mail: SHIWA.Mitsuharu@nims.go.jp.
Engineers [2]. Koda et al. studied the effect of corrosion cracking on the stiffness and fatigue strength of RC slabs by wheel-loading tests. They found that corrosion cracks reduce the fatigue strength of RC slabs significantly, whereas their static strength and stiffness showed smaller changes [3].

Erosion of the concrete under asphalt pavements is another important problem that can affect RC slabs in cases where large amounts of deicing salt are used. Erosion of the concrete of the RC slab is caused by combined actions, such as those of cyclic wheel loads, water, or freezing pressure. It is empirically known that horizontal cracks are induced along reinforcing bars before erosion occurs; debonding between the concrete and its reinforcement is a major cause of this horizontal cracking. Understanding the propagation of horizontal cracks is the key to elucidating the mechanism of degradation of RC slabs.

$\mathrm{AE}$ (acoustic emission) and elastic-wave-velocity 
measurements have been used to evaluate damage to RC slabs during running-wheel load tests $[4,5]$. When cracking occurs in an RC slab, the elastic-wave velocity decreases and the attenuation of the elastic wave increases. Consequently, attaching an AE sensor directly to the concrete is not a sustainable monitoring method. Furthermore, there are limitations on the measurement distance that depend on the nature of the fracture process.

In this study, we conducted a running-wheel load test on an RC slab specimen, and we attempted to evaluate vertical and horizontal cracking by means of two-channel AE measurements with a reinforcement rod (rebar) as a waveguide.

\section{Method and Materials}

\subsection{RC Slab and Running-Wheel Load Tests}

The specimens were 3,000 $\mathrm{mm}$ long, 2,000 $\mathrm{mm}$ wide, and had a thickness of $160 \mathrm{~mm}$ (Fig. 1). The characteristic compressive strength of the concrete was 20.7 MPa, and its Young's modulus was $21.7 \mathrm{GPa}$. The reinforcement material type was SD295A; the sizes of the main reinforcement and distributing bars were D16 and D13, respectively.
Fatigue testing with the running-wheel-load testing machine equipped with a steel tire was conducted as shown in Fig. 2. The wheel-loaded area extended from $500 \mathrm{~mm}$ to $2,500 \mathrm{~mm}(2,000 \mathrm{~mm})$. Fig. 3 shows the step loads used in the test. The equivalent fatigue cycle $N_{e}$ was calculated as follows:

$$
N_{e}=\left(L / L_{0}\right)^{12.76}
$$

where, $L_{0}$ is the reference load $\left(98 \mathrm{kN} ; N=1 \times 10^{0}\right.$ to $\left.1 \times 10^{5}\right), L$ is the applied load, $127.4 \mathrm{kN}\left(N=1 \times 10^{5}\right.$ to $\left.2 \times 10^{5}\right), 127.4 \mathrm{kN}\left(N=1 \times 10^{5}\right.$ to $\left.2 \times 10^{5}\right)$, $156.8 \mathrm{kN}\left(N=2 \times 10^{5}\right.$ to $\left.2.5 \times 10^{5}\right), 186.2 \mathrm{kN}(N=2$ $\times 10^{5}$ to $\left.3.0 \times 10^{5}\right)$, or $215.6 \mathrm{kN}\left(3 \times 10^{5}\right.$ to $\left.4.0 \times 10^{5}\right)$.

\subsection{AE Measurements}

Sixteen AE sensors were attached to the end of the distributing bar, as shown in Fig. 1. The resonant frequency of $\mathrm{AE}$ sensors was $60 \mathrm{kHz}$ with a 20-dB-gain preamplifier (R6I; Physical Acoustics Corp., Princeton Junction, NJ). An AE measurement system (Sensor Highway II, Mistras Group Co., Princeton Junction, NJ) recorded the waveform and AE parameters. In the AE monitoring, the sampling rate was $1 \mathrm{MHz}$ and the threshold level was set to $55 \mathrm{~dB}$ during cyclic loading.
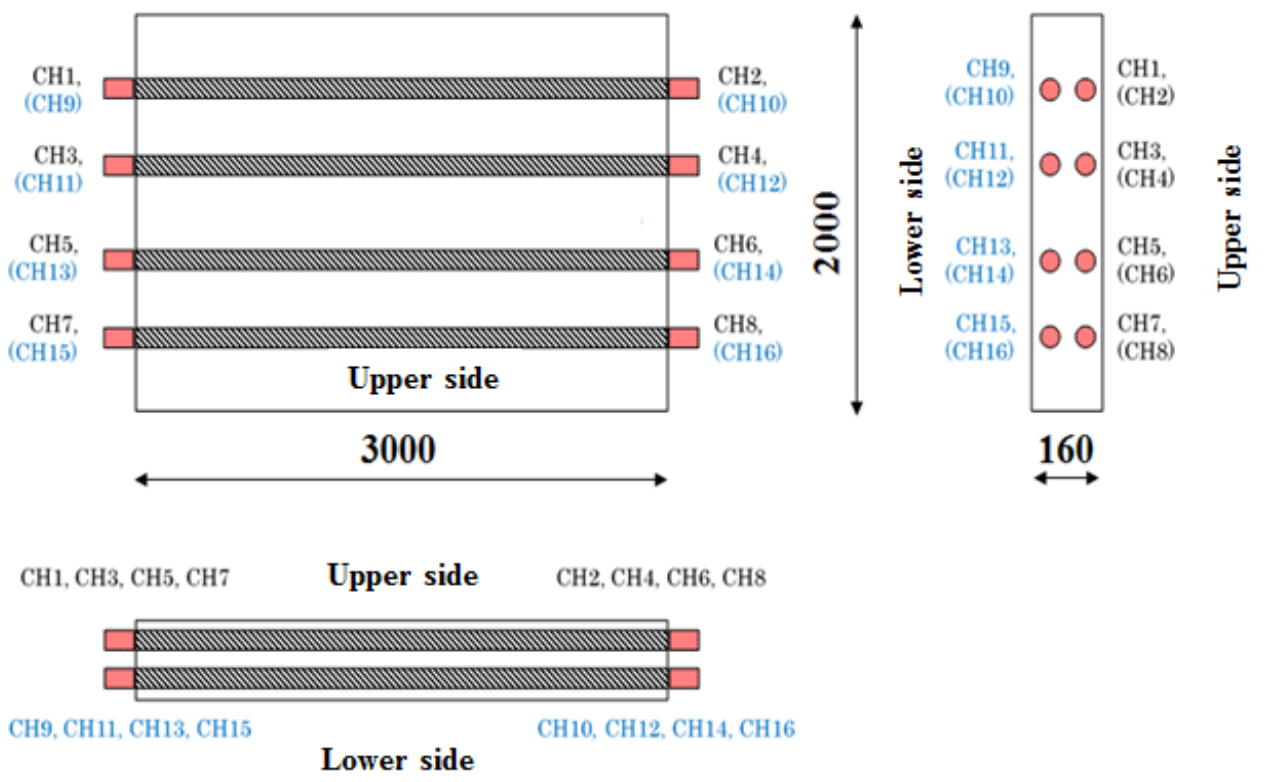

Fig. 1 The dimensions of RC slab specimen and mounting position for the 16 AE sensors. Photograph of the running-wheel load testing machine with a steel tire. 

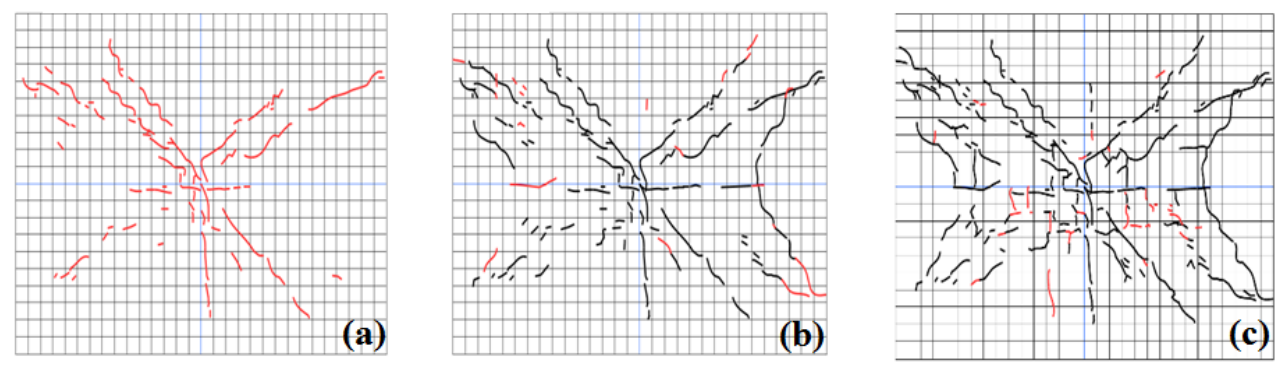

Fig. 2 Traces for surface cracking on the lower side of the RC slab for: (a) $N=2$; (b) $N=1,000$; (c) $N=50,000$ cycles.

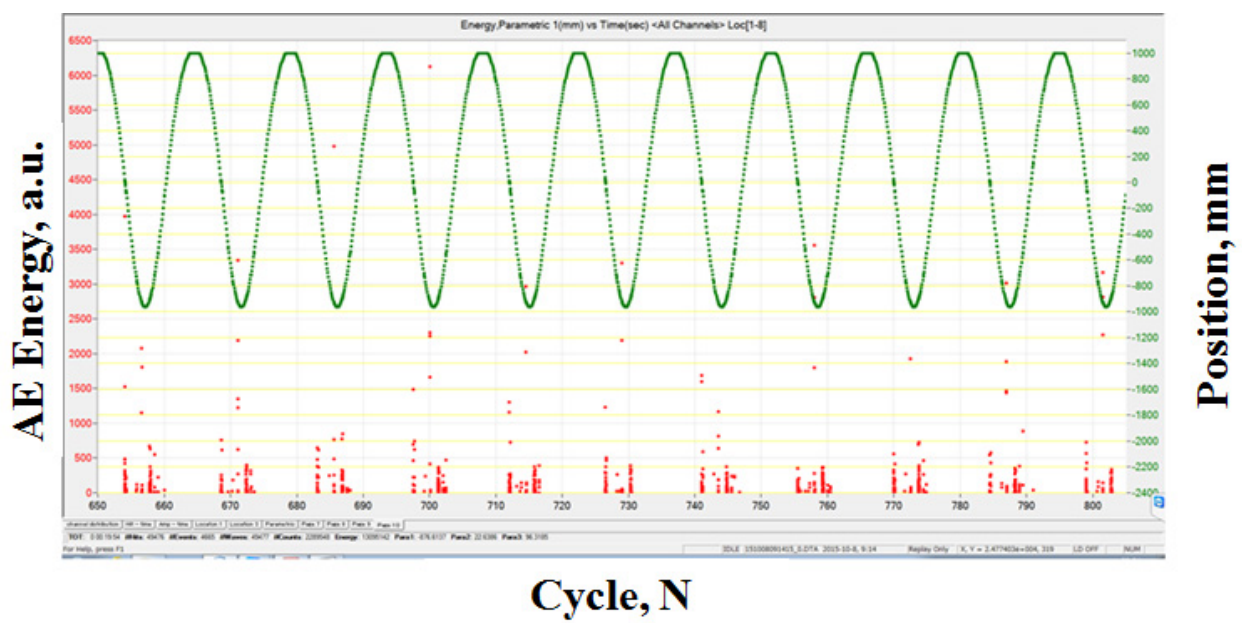

Fig. 3 The AE energy and the $0 \mathrm{kN}$ loading position of the RC slab as measured by a laser displacement meter.

\section{Results and Discussion}

\subsection{Lower-Side Surface Cracking of the RC Slab During Running-Wheel Loading}

Fig. 2 shows traces for surface cracks on the lower side of the RC slab for $N=2$ (Fig. 2a), $N=1,000$ (Fig. 2b), and $N=50,000$ cycles (Fig. 2c). The generated cracks were flexural cracks, observed in the parallel and perpendicular directions to the running-wheel load; the oblique direction of the cracks was due to torsion of the RC slab. Cracks were observed at the center of RC slab during the second cycle of loading; these subsequently expanded in the direction of the running-wheel load.

\subsection{Live-Load Deflection and AE Parameters}

Fig. 3 shows the AE energy and the $0 \mathrm{kN}$ loading position of the RC slab, as measured by using a laser displacement meter. Synchronized AE signals were generated by seams present on the rail in the loading machine. AE signals at the characteristic position were filtered to remove the noise from the seams on the rail during the running-wheel load test.

Figs. $4 \mathrm{a}$ and $4 \mathrm{~b}$ show the live-load deflection of the $\mathrm{RC}$ slab on the upper side (ch3-4) and the lower side (ch13-14), together with the cumulative AE events (Fig. 4a) and the AE energy (Fig. 4b). The live-load deflection gradually increased up to $1 \times 10^{4}$ cycles, and then increased rapidly after $8.3 \times 10^{6}$ cycles. After $1 \times 10^{4}$ cycles, AE events began to be generated continuously on both the upper and lower side. In the AE-active region, from $1 \times 10^{4}$ to $10^{5}$ cycles, $\mathrm{AE}$ events increased similarly on both sides. No active AE events were observed on either side between $1 \times 10^{5}$ and $10^{6}$ cycles. After $1 \times 10^{6}$ cycles, the AE events on the upper side increased rapidly compared with those on the lower side. In the case of AE energy, that on the upper side increased rapidly after $1 \times 10^{6}$ cycles, 


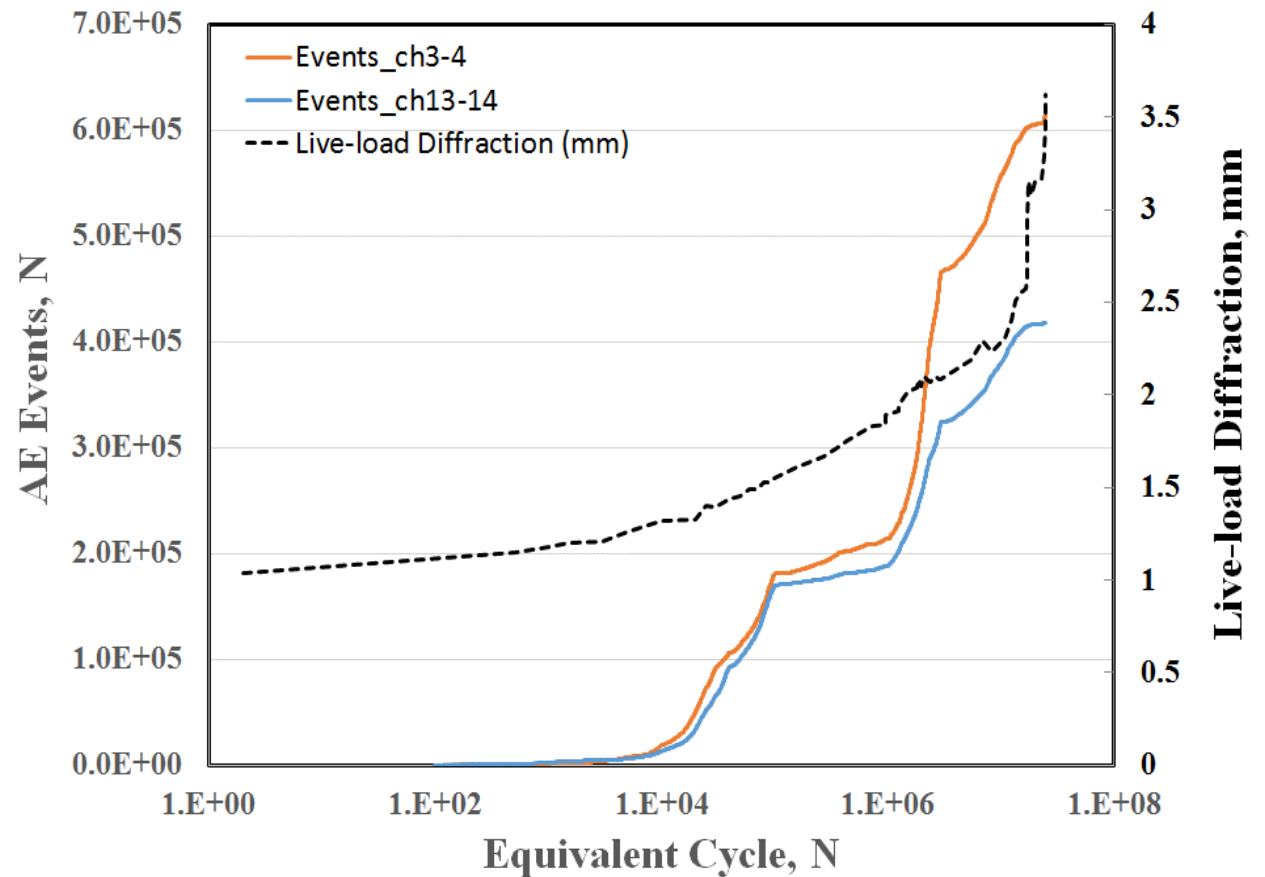

(a)

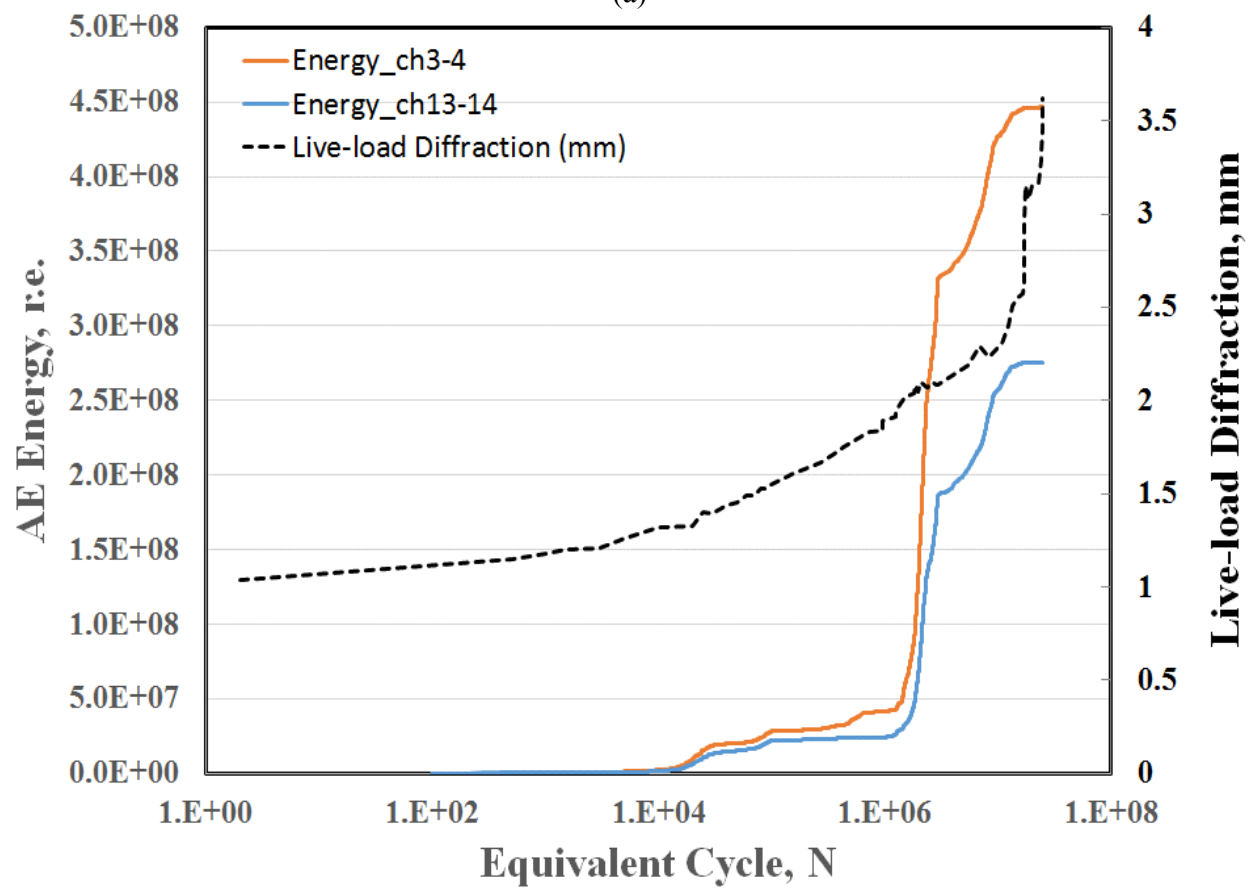

(b)

Fig. 4 Live-load deflection of the RC slab and the upper-side (ch3-4) and lower-side (ch13-14) cumulative: (a) AE events; (b) AE Energy.

compared with that on the lower side.

Figs. 5a and $5 \mathrm{~b}$ show the distributions of the $\mathrm{AE}$ source location for various equivalent cycle steps from $1 \times 10^{0}$ to $10^{3}\left(10^{\wedge} 3\right), 1 \times 10^{3}$ to $10^{4}\left(10^{\wedge} 4\right), 1 \times 10^{4}$ to $10^{5}\left(10^{\wedge} 5\right), 1 \times 10^{5}$ to $10^{6}\left(10^{\wedge} 6\right), 1 \times 10^{6}$ to $10^{7}$ $\left(10^{\wedge} 7\right)$, and up to $1 \times 10^{7}\left(10^{\wedge} 8\right)$ cycles on the upper side (Fig. 5a) and the lower side (Fig. 5b). The input wave velocity was $3,100 \mathrm{~m} / \mathrm{s}$, as measured by an impact source before the wheel load began running. On the upper side, the main AE source was located on 
the left-hand side ( 0 to $400 \mathrm{~mm}$ ) at $10^{\wedge} 7$ equivalent cycle steps. However, on the lower side, the main AE source was located in near the center (700 to $1,500 \mathrm{~mm})$ at $10^{\wedge} 5$ equivalent cycle steps. Therefore, the generated $\mathrm{AE}$ events at $10^{\wedge} 5$ equivalent cycle steps had to be mainly on the lower side, whereas the generated $\mathrm{AE}$ events at $10^{\wedge} 7$ equivalent cycle steps must have been mainly on the upper side.

To characterize the located AE sources, AE peak amplitude distribution (Fig. 6), peak-frequency distribution (Fig. 7), and the distribution of the ratio of the rise time to the peak amplitude (RA) (Fig. 8) on the upper side (a) and the lower side (b) for equivalent cycle steps from $1 \times 10^{0}$ to $10^{3}\left(10^{\wedge} 3\right), 1 \times 10^{3}$ to $10^{4}$ $\left(10^{\wedge} 4\right), 1 \times 10^{4}$ to $10^{5}\left(10^{\wedge} 5\right), 1 \times 10^{5}$ to $10^{6}\left(10^{\wedge} 6\right), 1$ $\times 10^{6}$ to $10^{7}\left(10^{\wedge} 7\right)$, and up to $1 \times 10^{7}\left(10^{\wedge} 8\right)$ cycles were determined and are shown in Figs. 6-8, respectively.

Figs. $6 \mathrm{a}$ and $6 \mathrm{~b}$ show the distributions of the AE peak amplitude distribution for various equivalent cycle steps from $1 \times 10^{0}$ to $10^{3}\left(10^{\wedge} 3\right), 1 \times 10^{3}$ to $10^{4}$ $\left(10^{\wedge} 4\right), 1 \times 10^{4}$ to $10^{5}\left(10^{\wedge} 5\right), 1 \times 10^{5}$ to $10^{6}\left(10^{\wedge} 6\right), 1$ $\times 10^{6}$ to $10^{7}\left(10^{\wedge} 7\right)$, and up to $1 \times 10^{7}\left(10^{\wedge} 8\right)$ cycles on the upper side (Fig. 6a) and the lower side (Fig. 6b). Three AE amplitude peaks were observed at 58, 79, and $85 \mathrm{~dB}$. The peak at $58 \mathrm{~dB}$ was observed at $10^{\wedge} 4$

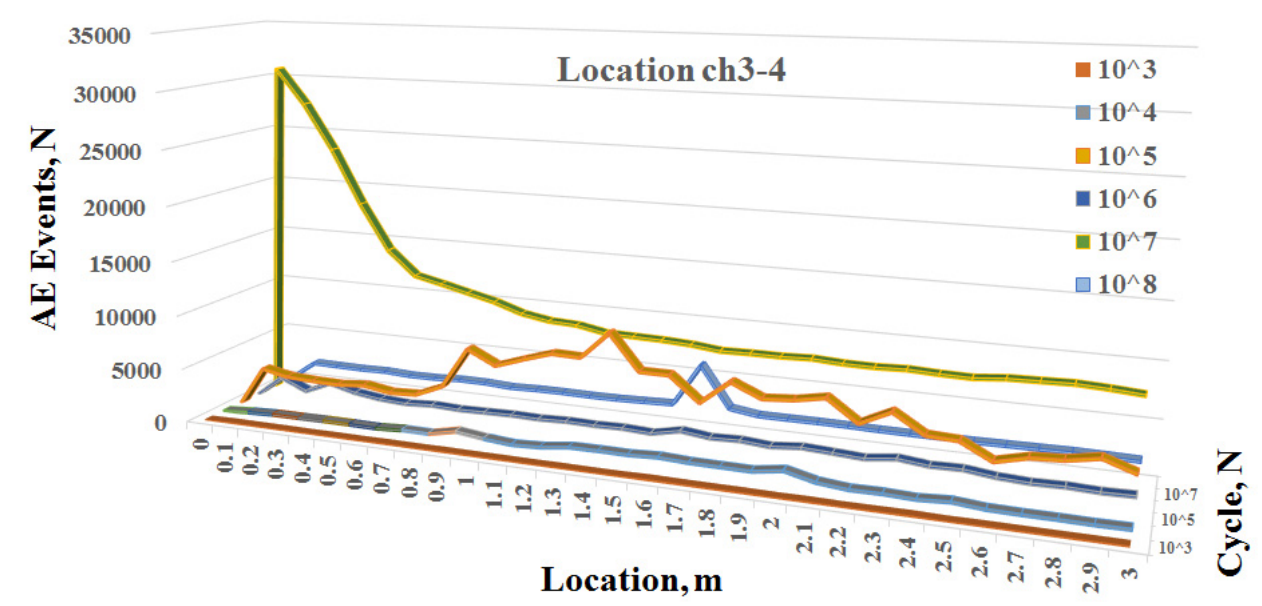

(a)

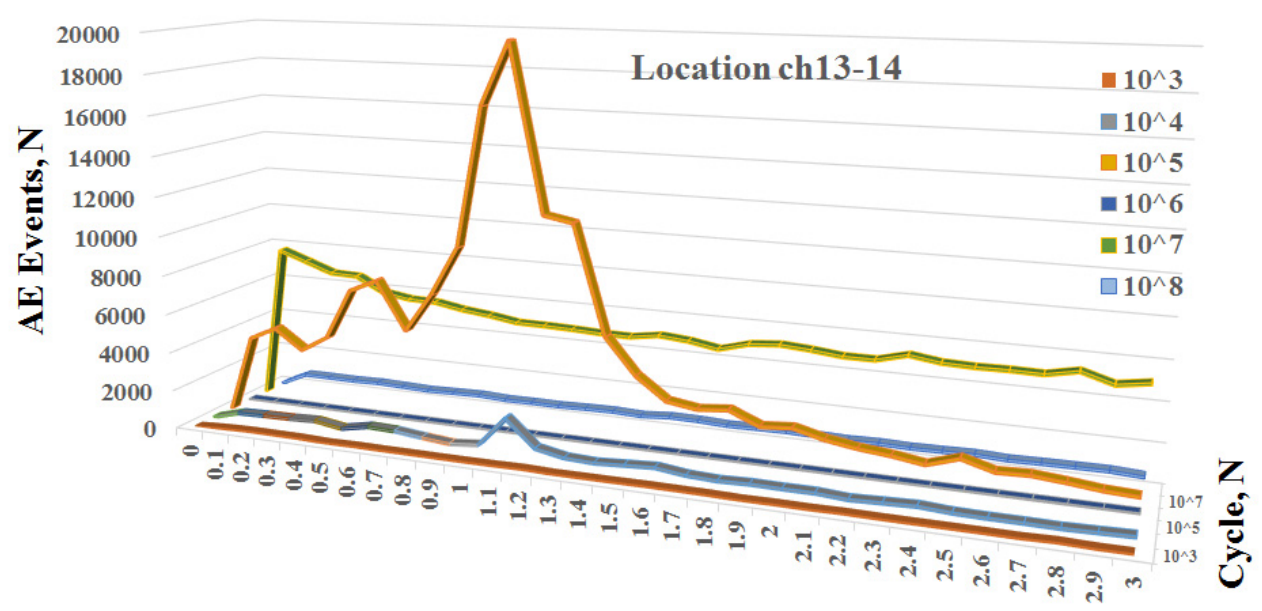

\section{Location, $\mathbf{m}$}

(b)

Fig. 5 AE source location distribution for equivalent cycle steps from $1 \times 10^{0}$ to $10^{3}\left(10^{\wedge} 3\right), 1 \times 10^{3}$ to $10^{4}\left(10^{\wedge} 4\right), 1 \times 10^{4}$ to $10^{5}\left(10^{\wedge} 5\right), 1 \times 10^{5}$ to $10^{6}\left(10^{\wedge} 6\right), 1 \times 10^{6}$ to $10^{7}\left(10^{\wedge} 7\right)$, and up to $1 \times 10^{7}\left(10^{\wedge} 8\right)$ cycles for: (a) the upper side; and (b) the lower side. 


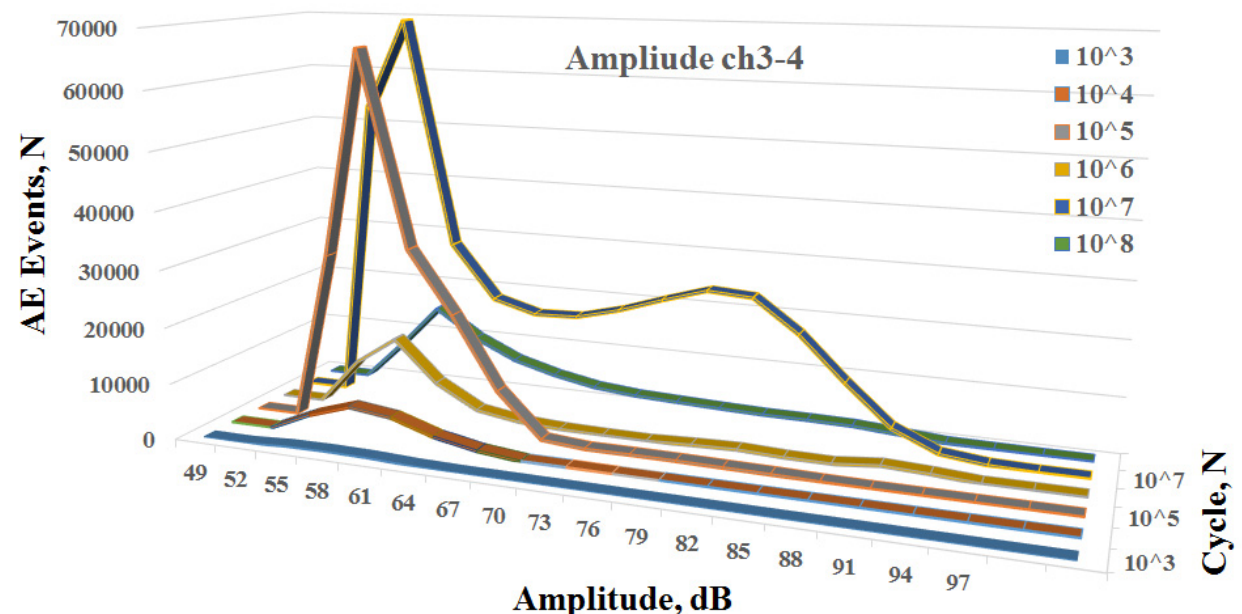

(a)

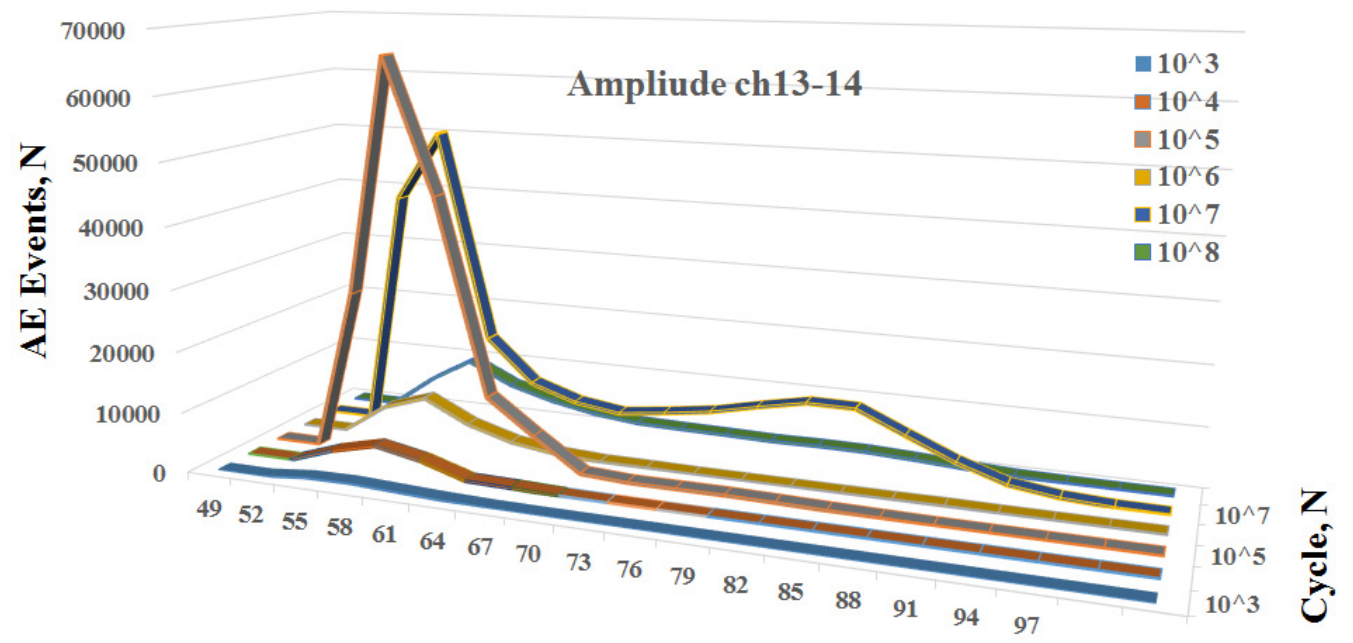

Amplitude, dB

(b)

Fig. 6 AE peak-amplitude distribution on: (a) the upper side; and (b) the lower side for equivalent cycle steps from $1 \times 10^{0}$ to $10^{3}\left(10^{\wedge} 3\right), 1 \times 10^{3}$ to $10^{4}\left(10^{\wedge} 4\right), 1 \times 10^{4}$ to $10^{5}\left(10^{\wedge} 5\right), 1 \times 10^{5}$ to $10^{6}\left(10^{\wedge} 6\right), 1 \times 10^{6}$ to $10^{7}\left(10^{\wedge} 7\right)$, and up to $1 \times 10^{7}\left(10^{\wedge} 8\right)$ cycles.

equivalent cycle steps on both the upper and lower sides. In particular, peaks were generated after $10^{\wedge} 5$ and $10^{\wedge} 7$ equivalent cycle steps. On the other hand, at $10^{\wedge} 7$ equivalent cycle steps, peaks of 79 and $85 \mathrm{~dB}$ were generated on the upper side and lower side, respectively, as shown in Fig. 6.

There were two AE peak frequencies: $30 \mathrm{kHz}$ and
$60 \mathrm{kHz}$. The peaks at $30 \mathrm{kHz}$ were observed at $10^{\wedge} 4$ equivalent cycle steps on both the upper and lower sides. In particular, peaks were generated at $10^{\wedge} 5$ and $10^{\wedge} 7$ equivalent cycle steps. On the other hand, at $10^{\wedge} 7$ equivalent cycle steps, a peak at $60 \mathrm{kHz}$ was generated on the lower side, as shown in Fig. 7.

In the case of the RA value, different peak patterns 


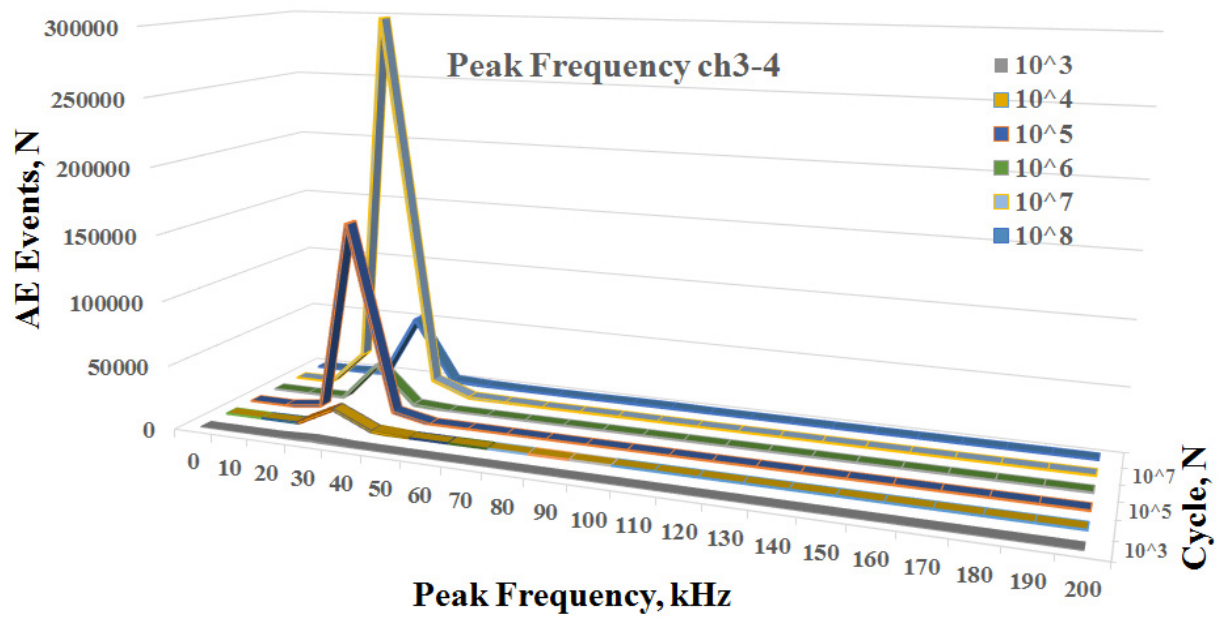

(a)

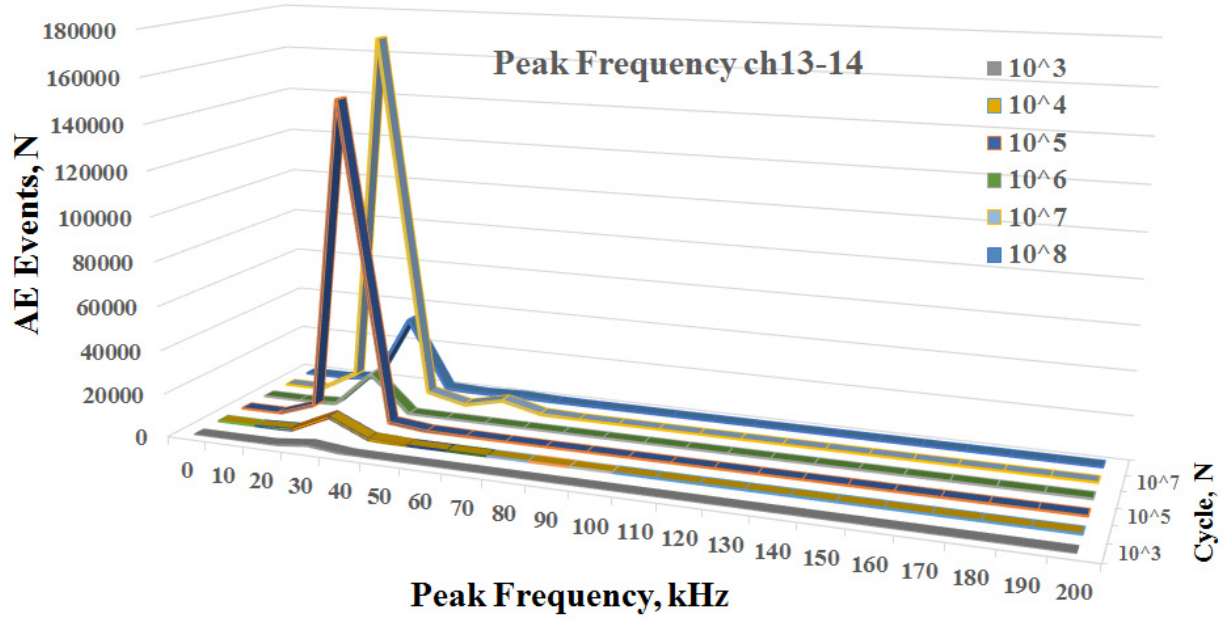

(b)

Fig. 7 AE peak-frequency distributions on: (a) the upper side; and (b) lower side in equivalent cycle steps from $1 \times 10^{0}$ to $10^{3}\left(10^{\wedge} 3\right), 1 \times 10^{3}$ to $10^{4}\left(10^{\wedge} 4\right), 1 \times 10^{4}$ to $10^{5}\left(10^{\wedge} 5\right), 1 \times 10^{5}$ to $10^{6}\left(10^{\wedge} 6\right), 1 \times 10^{6}$ to $10^{7}\left(10^{\wedge} 7\right)$, and up to $1 \times 10^{7}\left(10^{\wedge} 8\right)$ cycles.

were observed in the upper side and the lower side. A peak RA value of 100 was observed on both the upper and lower sides at $10^{\wedge} 5$ equivalent cycle steps, whereas a peak value of 10 was observed on both the upper and lower sides at $10^{\wedge} 7$ equivalent cycle steps, as shown in Fig. 8.
In previous running-wheel load tests, vertical cracks occurred on the lower side in the first stage of the testing and horizontal cracks occurred under the upper side in the final stage of testing. On the basis of the $\mathrm{AE}$ analysis, the vertical cracks should propagate after $1 \times 10^{4}$ cycles, whereas horizontal cracks should 


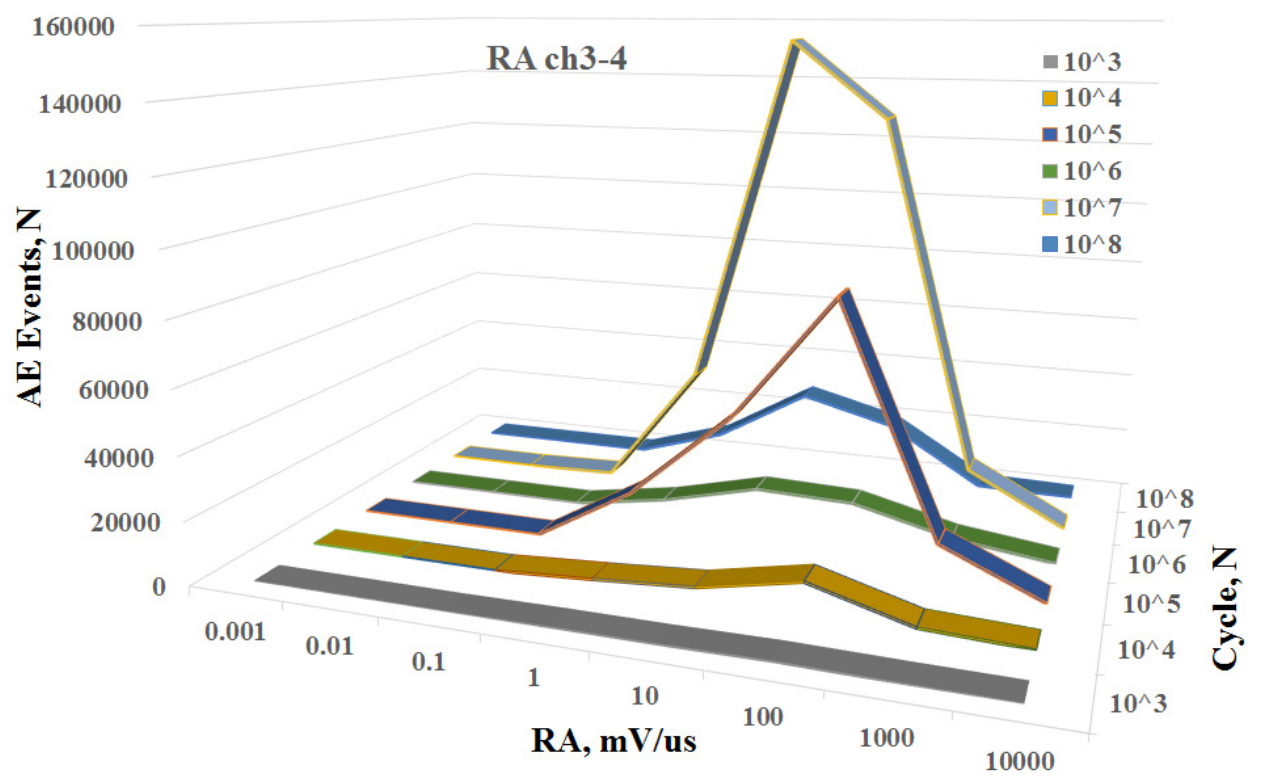

(a)

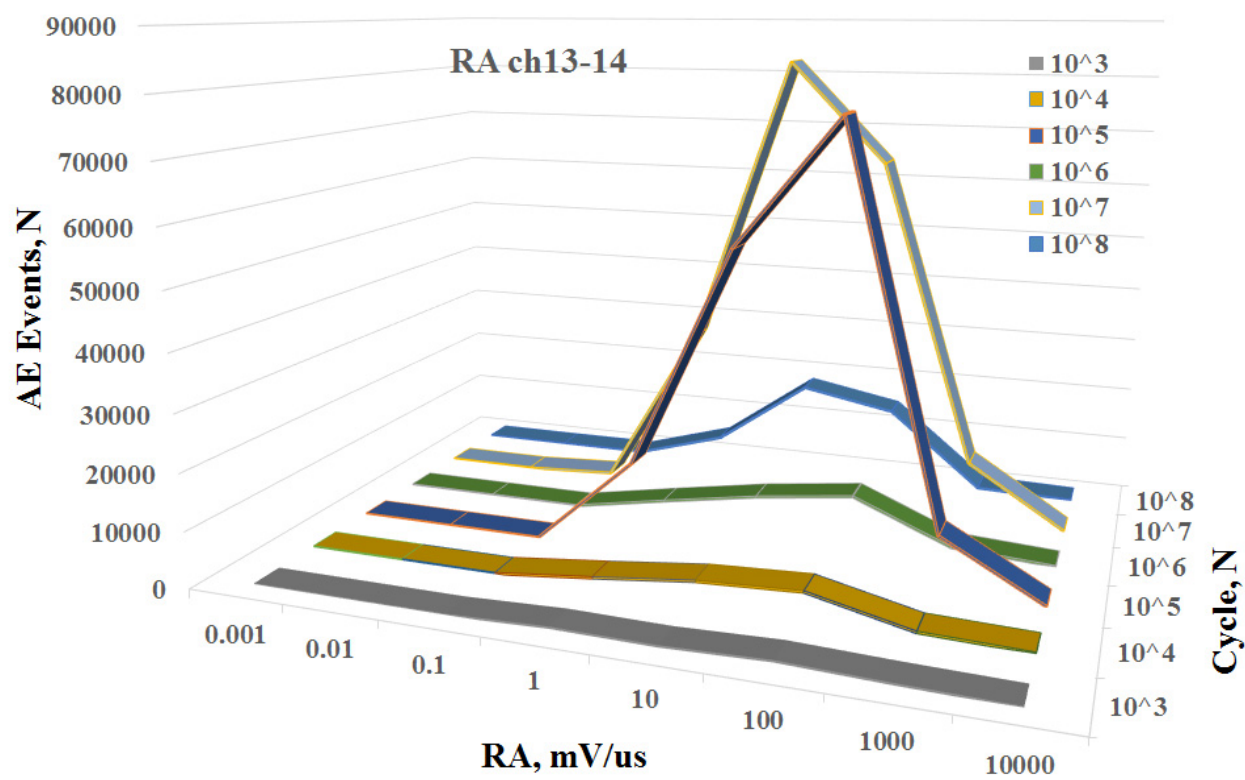

(b)

Fig. 8 RA values distribution on: (a) the upper side; and (b) lower side in equivalent cycle steps from $1 \times 10^{0}$ to $10^{3}\left(10^{\wedge} 3\right), 1$ $\times 10^{3}$ to $10^{4}\left(10^{\wedge} 4\right), 1 \times 10^{4}$ to $10^{5}\left(10^{\wedge} 5\right), 1 \times 10^{5}$ to $10^{6}\left(10^{\wedge} 6\right), 1 \times 10^{6}$ to $10^{7}\left(10^{\wedge} 7\right)$, and up to $1 \times 10^{7}\left(10^{\wedge} 8\right)$ cycles.

propagate after $1 \times 10^{7}$ cycles. AE parameters characteristic of the vertical cracks are an amplitude of $58 \mathrm{~dB}$, a peak frequency of $30 \mathrm{kHz}$, and an RA value of 100 , whereas those of horizontal cracks are an amplitude of $85 \mathrm{~dB}$, a peak frequency of $60 \mathrm{kHz}$, and an RA value of 10 .

\section{Conclusions}

Running-wheel load tests were conducted on an RC slab specimen to evaluate vertical and horizontal cracks by means of two-channel acoustic emission (AE) measurements with reinforcement rods (rebar) as waveguides. The AE waveguide measurement over a 
length of $3 \mathrm{~m}$ detected fractures as vertical and horizontal cracks in the RC slab:

(1) Synchronized AE signals were generated by seams present on the rail in the loading machine. AE signals at the characteristic position were filtered to remove the noise from the seams on the rail during the running-wheel load test;

(2) The live-load deflection gradually increased up to $1 \times 10^{4}$ cycles, and then increased rapidly after 8.3 $\times 10^{6}$ cycles;

(3) AE events began to be generated continuously on both the upper and lower side after $1 \times 10^{4}$ cycles. In the $\mathrm{AE}$ events and $\mathrm{AE}$ energy, two types of $\mathrm{AE}$ phenomena, active region and inactive region were observed;

(4) In the distributions of the AE source location for various equivalent cycle steps, the generated $\mathrm{AE}$ events at $10^{\wedge} 5$ equivalent cycle steps had to be mainly on the lower side, whereas the generated $\mathrm{AE}$ events at $10^{\wedge} 7$ equivalent cycle steps must have been mainly on the upper side;

(5) We concluded that vertical cracks propagated after $1 \times 10^{4}$ cycles on the lower side, and that horizontal cracks propagated after $1 \times 10^{7}$ cycles on the upper side;

(6) The vertical cracks were characterized by an $\mathrm{AE}$ amplitude of $58 \mathrm{~dB}$, a peak frequency of $30 \mathrm{kHz}$, and an RA value of 100 . The horizontal cracks were characterized by an $\mathrm{AE}$ amplitude of $85 \mathrm{~dB}$, a peak frequency of $60 \mathrm{kHz}$, and an RA value of 10 .

\section{Acknowledgments}

This work was supported by Council for Science, Technology and Innovation (CSTI), Cross-ministerial Strategic Innovation Promotion Program (SIP), "Infrastructure maintenance, renovation and management" (Funding agency: JST).

\section{References}

[1] Matsui, S. 2009. "Review of Researches and Technologies on Highway Bridge Decks by Using Wheel Running Machines." Journal of Structural Engineering 55A: 1408-19. DOI: 10.11532/structcivil.55A.1408. (in Japanese)

[2] Japan Society of Civil Engineers. 2007. Standard Specification for Concrete Structure: Maintenance. Tokyo: Japan Society of Civil Engineers, 215-32.

[3] Koda, Y., Furuyama, Y., and Iwaki, I. 2008. "Experimental Study on Deterioration and Load-Carrying Capacity of RC Deck Damaged by Chloride Attack." Proceedings of the Japan Concrete Institute 30 (1): 813-8. (in Japanese)

[4] Ohno, K., Uji, K., and Ueno, A. 2014. "Application of Acoustic Emission and Elastic Wave to Buckle Plate Slab under Wheel Load Running Test." JSNDI, Progress in Acoustic Emission XVII, 1-6.

[5] Shiotani, T., Kawai, K., Momok. S., Chai, H., Ohnishi, H., and Kamada T. 2010. "Damage Identification of RC Bridge Decks with AE Monitoring." JSNDI, Progress in Acoustic Emission XV, 211-6. 